\title{
INSTABILITY AT THE PAL LOCUS IN ANTIRRHINUM MAJUS
}

\section{MULTIPLE ALLELES PRODUCED BY MUTATION OF ONE ORIGINAL UNSTABLE ALLELE}

\author{
J. R. S. FINCHAM* and B. J. HARRISON \\ John Innes Institute, Bayfordbury, Hertford, Herts.
}

Received 4.vii.66

The pallida ( $p a l$ ) locus of Antirrhinum majus is one of the loci involved in the formation of anthocyanin pigment, both in the flowers and, though less conspicuously, in the vegetative parts. Alleles of the pallida-recurrens ( par $^{\text {rec }}$ ) type are mutable, giving cyanic spots and flakes against an ivory or yellow background in the flowers and against a green background in the stem and cotyledons. Mutations also occur in the germ cells giving fully mutant plants in the following generation.

The first paper in this series (Harrison and Fincham, I964) described the effects of different temperatures on the frequencies of somatic and germinal mutation of palrec. It was shown that mutation, both somatic and germinal, was much more frequent at $15^{\circ} \mathrm{C}$. than at $25^{\circ} \mathrm{C}$., and that the timing of mutations could be controlled by manipulation of the temperature at which the plants were cultured.

One of the most interesting points to emerge was that, at $15^{\circ} \mathrm{C}$., plants carrying parec in a genetic background favouring high mutation frequency mutated not only to the fully pigmented " wild type" (Pal) but also to several other distinct phenotypes which were assumed to be due to other alleles at the pallida locus. In this paper data are presented which substantiate this assumption, and a comparison is made of the phenotypes determined by the various alleles and their different responses to temperature changes.

\section{MATERIALS AND METHODS}

\section{(i) Antirrhinum stocks and origin of mutants}

The origins of the stocks used in this study were outlined in the previous paper (Harrison and Fincham, I964). The phenotypes determined by new mutants have generally been observed in heterozygotes either with paltin or paltub, both of which alleles give practically acyanic flowers when homozygous. Our two stocks homozygous for palrec, previously designated (low) palrec and (high) pal, ${ }^{\text {rec }}$ are now known to differ from each other chiefly in a single gene modifying the mutation frequency of

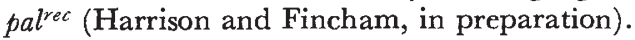

The majority of the mutants discussed here arose from the experiment described in our 1964 paper, in which $F_{1}$ plants from the cross (high) palrec $\times$ paltub were selfpollinated and a large number of seedlings raised from the seed obtained. The

* Present address: Department of Genetics, The University, Leeds 2. 
original (high) palrec stock was homozygous for delilah (del), a recessive which has the effect of abolishing anthocyanin pigmentation in the corolla tube, and the paltub stock with which it was crossed was homozygous for sulfurea (sulf), a recessive which spreads the yellow aurone pigment, usually confined to the corolla "lip", to the corolla lobes. Hence many of the mutants found in the $F_{2}$ generation were either heterozygous or homozygous for one or both of these recessives, neither of which is linked to pal. Mutants were tested by selfing and also by crossing to plants homozygous for paltin. One of the paltin tester plants was heterozygous for del, and so the latter marker segregated in some of the progeny families from the test-crosses; sulf or $d e l$ or both were either homozygous or segregating in many of the families resulting from selfing mutant plants. Since neither sulf nor del interfered seriously with scoring of pal mutants their presence in some of the families will be ignored in the tabulation of the results.

\section{(ii) Growth at controlled temperatures}

Controlled temperature rooms were used as described previously (Harrison and Fincham, 1964) except that a 12 -hour day was used at both $15^{\circ} \mathrm{C}$. and $25^{\circ} \mathrm{C}$. Plants whose floral phenotypes were to be observed at the two temperatures were either grown at these temperatures throughout their development, or transferred to the constant temperature rooms from the greenhouse shortly before the onset of flower development. It was shown in our earlier paper that it was the temperature during flowering, rather than the temperature before flowering, which was critical in determining the expression of palrec in the flowers.

(iii) Extraction and chromatographic separation of pigments

The methods of Harborne (1963) were followed.

\section{INHERITANCE OF THE NEW PAL MUTANTS}

The great majority of the new pal mutants were first observed in heterozygotes with either $p a l^{t u b}$ or $p a l^{\text {rec }}$. The complete range of pal alleles could be recognised in compounds with pal $l^{t u b}$, but only those determining medium or high levels of pigment could be distinguished in compounds with palrec. This is because only a fairly strong and uniform background colour could be easily seen in combination with the numerous deep red spots and sectors determined by palrec.

The 96 mutants from the main experiment with other than full-red phenotypes were clearly the result of considerably fewer than 96 independent mutations. There was a strong tendency for mutants of closely similar phenotype to occur together among the progeny of a single capsule, and in such cases it seems very probable that a single mutation occurred prior to meiosis in the sub-epidermal cell layer of one or other parent (a single anther was usually used for each pollination). Mutants were divided into different named classes on the basis of their own phenotypes and of those of their progeny. Those which fell into the same phenotypic category but which came from different plants or from widely separated capsules on the same plant were given different numbers following the allele designation. Those of similar phenotype from the same capsule were assigned the same name and number since they probably carried the same mutation. Usually, in such cases, several plants supposedly carrying the same mutation were progeny-tested but, in the interests of a compact presentation of the 


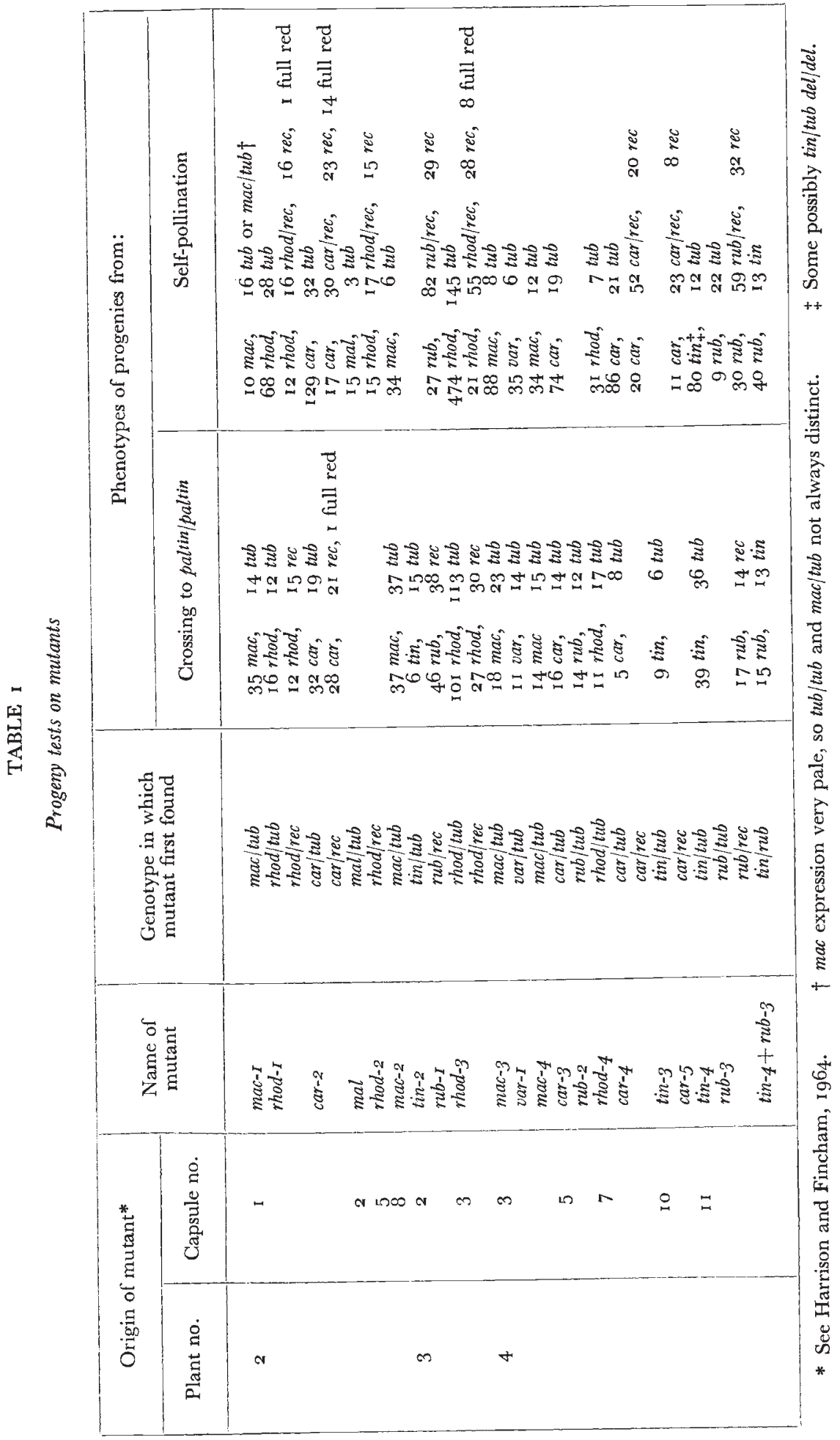


results, the resulting families (which were homogeneous) were added together to give the numbers listed in table $\mathrm{I}$. It is possible that in some cases similar mutants of independent origin were present by chance in the same capsule and were wrongly considered as identical. In any case the main conclusions would remain unaltered, and no confusion can arise from this source since no more than one representative of each group of supposedly identical mutants was finally kept.

The results of further breeding tests on pal mutants are summarised in table I. Crosses to homozygous pal ${ }^{\text {tin }}$ gave approximately I: I segregations of $p a l^{t u b}$ or pal rec from the new mutant type. In each case the mutant phenotype showed a high degree of constancy, except that in those crosses in which homozygous del was segregating the del/del pal $^{(\text {mutant })} /$ pal $^{\text {tin }}$ plants showed somewhat paler pigmentation than the corresponding Del plants in the corolla lobes, as well as absence of anthocyanin in the corolla tube. In families in which pal rec was segregating a few $\mathrm{Pal}$ plants, presumably due to further mutation, were obtained, but among the families segregating for pal ${ }^{t u b}$ no such plants were seen, neither was there any reversion to the $p a l^{r e c}$ phenotype.

The progenies resulting from selfing $p a l^{(\text {mutant })} / p a l^{t u b}$ plants showed, in most cases, an approximation to a $3:$ I ratio of mutant and pal ${ }^{\text {tub }}$ phenotypes, though there was a rather general significant shortage of the pal ${ }^{t u b}$ homozygotes. Among the mutant progeny there tended to be two classes with respect to intensity of pigmentation occurring in proportions which strongly suggest that a homozygous mutant produces more pigment than a plant in which the mutant allele is heterozygous with pal ${ }^{t u b}$. In other words, the mutant alleles seem to be incompletely dominant, differing in this respect from $\mathrm{Pal}$, which is almost or quite dominant in compound with pal $l^{t u b}$ or pal ${ }^{t i n}$. The presumed homozygotes and heterozygotes could not always be scored with certainty, however, and they are not distinguished in table $\mathrm{I}$. In addition to the variation seemingly due to incomplete dominance, the general diluting effect of homozygous del was also evident in those families in which this marker was segregating. With these qualifications, and with one exception noted below, each mutant bred true. The original palrec allele was never recovered, except perhaps in one somatic mutant sector (see section 3 below).

In the case of the progenies resulting from selfing pal $^{\text {(mutant })} /$ pal $^{\text {rec }}$ plants, three progeny classes could be distinguished: $\mathrm{pal}^{(\text {mutant })} \mid \mathrm{pal}^{(\text {mutant })}$, pal $l^{\text {(mutant) }} \mid$ pal ${ }^{\text {rec }}$ and pal ${ }^{r e c} / p^{2} l^{r e c}$. These occurred, in most cases, in a reasonable approximation to a I: 2: I ratio. Occasional $\mathrm{Pal}$ progeny could be attributed to further mutation of pal $^{\text {rec }}$.

The data as a whole, summarised in table I, lend strong support to the assumption that all the mutants were due to mutations at the unstable pal locus.

Following our original crop of mutants we have obtained numerous

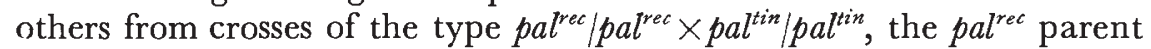
having a genotype favouring a very high mutation frequency (Harrison 
and Fincham, in preparation). Most of these further mutants resembled mutants which had been obtained previously and were not further studied. Two, however, were novel and were investigated by further breeding. The first, described below as tubocolorata-2, was self-pollinated, and in the resulting small family there were eight plants showing the $t u b-2$ phenotype and five homozygous paltin. The second, called rubra-recurrens, has been selfed and also crossed to homozygous $p a l^{t u b}$ and the results (which are still incomplete) are so far consistent with a new allele at the pallida locus.

\section{STABILITY OF THE NEW ALLELES}

Two of the new alleles are noticeably unstable. Three out of ten plants obtained from selfing a homozygous pal $^{\text {mac-3 }}$ plant have shown a new phenotype which we interpret as due to a new stable allele. A similar phenotype was seen in one out of 24 plants from a cross of homozygous $p a l^{m a c}$ to $p a l^{t u b}$. As we report below, pal ${ }^{\text {mac }}$ determines a phenotypic pattern which suggests mutability. In one pal ${ }^{\text {mac-3 }}$ plant a sector of a flower showed a phenotype suggestive of reverse mutation to $p a l^{r e c}$.

In the case of pal rubra-recurrens no germinal mutations have so far been obtained, but the pattern of flaking (white on red) seen in heterozygotes with pal $l^{t i n}$ or $p a l^{t u b}$ is strongly suggestive of further mutation to an allele determining a near-acyanic phenotype.

\section{DESCRIPTION AND CLASSIFICATION OF MUTANTS}

Our nomenclature for pal alleles has followed that of Kuckuck and Schick (1930). We have been guided both by the descriptions published by the German authors and by direct comparisons with three already named pal alleles in our stock collection. These three, patin, $p^{t t u b}$ and pal $^{\text {car }}$, were all supplied to us by Dr D. R. Sampson of the Canadian Department of Agriculture; they will be referred to as tin-I, tub-I and car-I respectively to distinguish them from new mutations of the same general types to which we have attached the same names with different numbers.

In the following account of mutant phenotypes the descriptions in quotation marks are translated from Kuckuck and Schick:

rubra. " "palrub/pal plab plants have reddish-pink flowers." The alleles which we have called rubra give, in homozygotes, only slightly less anthocyanin than Pal. In compound with pal ${ }^{t i n}$ or pallub, however, they are clearly less potent than $\mathrm{Pal}$, and $\mathrm{pal}^{\mathrm{rub}} / \mathrm{pal}^{r e c}$ gives deep red flakes on a lighter red background (plate I).

carnea. "pal $l^{\text {car }} /$ pal $^{\text {car }}$ plants have flesh-coloured flowers." The new alleles designated carnea are more or less similar to pal ${ }^{\text {car-x }}$, though they differ somewhat in the amounts of pigment which they typically produce. 
rhode. "pal'hode/palrhode plants have light flesh-coloured flowers." "Typical " rhode gives considerably lighter flowers than carnea, but some alleles, for instance pal ${ }^{r h o d \cdot 3}$, could have been considered as falling at the pale end of the carnea range. In fact there is nothing to show that there are any clear lines to be drawn between

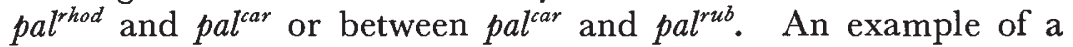
relatively dark carnea allele is $p a l^{c a r-3}$, which is only slightly lighter than some rubra alleles. One could probably find a continuous series of mutants linking the palest rhode (which perhaps correspond to Kuckuck and Schick's malacea) with the darkest rubra. Table 2 shows estimates of the amounts of anthocyanin pigment in flowers of "typical" members of the series.

TABLE 2

Anthocyanin contents of flowers homozygous for various pal alleles

\begin{tabular}{|c|c|c|}
\hline Allele & $\begin{array}{l}\text { Optical density } \\
\text { at } 520 \mathrm{~m} \mu\end{array}$ & $\%$ of $\mathrm{Pal}$ \\
\hline $\begin{array}{l}\text { Pal } \\
\text { palrub-3 } \\
\text { palcar-2 } \\
\text { palrhod-I } \\
\text { paltub-2 } \\
\text { paltin-I }\end{array}$ & $\begin{array}{l}0 \cdot 69 \\
0 \cdot 66 \\
0 \cdot 315 \\
0 \cdot 082 \\
0 \cdot 012 \\
0 \cdot 00\end{array}$ & $\begin{array}{r}100 \\
95 \\
45 \\
12 \\
2 \\
0\end{array}$ \\
\hline
\end{tabular}

Three flowers of each type were extracted in $7 \mathrm{ml}$. $0 \cdot \mathrm{I} ~ \mathrm{~N} \mathrm{HCl}$, the filtered extract was extracted with ethyl acetate to remove copigments, diluted tenfold with $0^{\circ} \cdot \mathrm{N} \mathrm{HCl}$, and its absorption spectrum in the range $420-600 \mathrm{~m} \mu$ was measured in a recording spectrophotometer. The spectra were identical with an absorption maximum at $520 \mathrm{~m} \mu$.

malacea. "pal ${ }^{\text {mal }} \mid$ pal $^{\text {mal }}$ plants have pink tinged flowers." We found only one mutant which might have been similar to the original malacea, and this could have been considered as a pale representative of the rhode class.

tubocolorata. "pal ${ }^{t u b} / \mathrm{pal}^{\text {tub }}$ plants develop the red colour only in a very small zone at the base of the flower tube ... this spot of colour is almost completely concealed by the calyx. ..." Our stock $p a l^{t u b \cdot x}$ corresponds to this description. The new allele which we call pal ${ }^{t u b-2}$ differs in that the colour extends in a light flush for some distance up the corolla tube, though never reaching the lobes of the corolla (plate I).

tincta. "pal ${ }^{\text {tin }} /$ pal tin $^{\text {in }}$ plants have ivory-coloured flowers. If the plants are at the same time cornuta/cornuta they form light red colouring at the base of the spur." Our stock paltin, which may not be identical to the originally described tincta, has ivory flowers when grown in the greenhouse, but outdoors it frequently develops a faint and somewhat spotty flush round the margins of the corolla lobes and occasionally one sees a spot as dark and well defined as 
in palec plants. The new alleles patin-2 pal $^{\text {tin-3 }}$ and pal tin-4 (especially the last) showed this same tendency to a somewhat greater degree (plate I).

maculosa. " $p a l^{\text {mac }} / p a l^{m a c}$ plants have flowers with irregularly distributed indistinct spots in which the red colour corresponds to some extent to the tone of the malacea flower" (i.e. pale magenta). Our new palmac-3 (plate I) corresponds to this description except that, in addition to the plentiful pale spots and sectors there are some darker spots, particularly at the base of the corolla tube and on the "lip" of the corolla. As noted above, this allele mutates in the germ cells to give stable mutants which exhibit uniformly the level of pigmentation seen only in the spots of the original pal mac $^{\text {ma }}$ plant. Our other new pal ${ }^{m a c}$ alleles, while rather similar in pattern, gave many fewer spots (plate I).

Just as the series rubra-carnea-rhode-malacea appears to form a continuum, so it seems impossible to draw a firm line between alleles of the tincta class which produce a more distinct tinge of pigment and those of the maculosa type having a low level of expression. There was, in fact, no sharp distinction between tin-2 and tin-3, on the one hand, and mac-I, mac-2, mac-4 and $m a c-5$ on the other (mac-3 produced much more pigment than any of these). The various tin and mac alleles are also somewhat similar in their expression to that of palrec in genetic backgrounds which depress mutation frequency. They all produce occasional well defined dark spots, presumably by mutation to Pal, and the faint flush which they often show could be interpreted as due to numerous very late mutations affecting single cells.

varicolor. This is a name we have adopted to describe a type of allele which does not appear to correspond to any of Kuckuck and Schick's descriptions. Plants of genotype palvar-I $/$ palvar-I (cf. table I) have (when they are not also homozygous for delilah) a concentration of pigment at the base of the corolla tube, very little on the rest of the tube, a good deal on the lower "lip " of the corolla, and a heavy concentration on the central upper part of the corolla in the angle between the two upper lobes. There is also pigment around the lower outer margins of the upper lobes, but only very dilute anthocyanin in the rest of the flower. The overall amount of pigment is rather like that in $p a l^{r \text { hod }} /$ pal $^{\text {rhod }}$ plants, but the distribution of pigment in the latter is much less uneven though it does show some concentration at the base of the corolla tube and between the upper lobes. In pal rode there is much more pigment on the upper part of the corolla tube. The allele referred to as var-2 arose in two steps via mac-3, and is rather similar in its effect to var-I, though perhaps giving rather less contrast between the dark and light areas of the flower. Some of the different patterns are shown in plate I. 


\section{EFFECT OF TEMPERATURE ON EXPRESSIONS OF THE DIFFERENT ALLELES}

It was shown in the previous paper (Harrison and Fincham, I964) that temperature had a critical effect on the expression of pal ${ }^{\text {rec }}$. Plants homozygous for various of the pal alleles were grown in constant temperature rooms at $15^{\circ} \mathrm{C}$. and $25^{\circ} \mathrm{C}$. during the period of flower development. The effects on floral phenotype are summarised in table 3 .

\section{PIGMENTS IN PLANTS CARRYING VARIOUS PAL ALLELES}

Alcoholic extracts were made of flowers from plants homozygous for

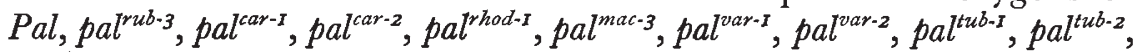
pal tin-I and pal rec. The extracts were concentrated to a volume of about $0^{\cdot} \mathrm{I} \mathrm{ml}$. for each flower extracted and two successive $2 \mu \mathrm{l}$. samples were superimposed near the corner of a Whatman no. I paper sheet. The chromatograms were developed in one dimension with $n$-butanol: acetic acid: water (BAW, 4: $1: 5 \mathrm{v} / \mathrm{v}$, upper phase), and in the second dimension with I 5 per cent. (v/v) acetic acid (Harborne, I965). Fig. I shows the pattern of spots seen in visible and ultraviolet light in extracts of pal mutants.

The anthocyanin spot, though it varied greatly in intensity between one allele and another, was in the same position in all the chromatograms and can be presumed to be cyanidin 3-rutinoside, as in Pal plants (Scott-Moncrieff, 1930). In the presence of the homozygous recessive eosina this pigment is replaced by pelargonidin 3-rutinoside, but eos was not segregating in any of the families relevant to this paper. It seems that gene substitution at the pal locus makes no difference to the nature of the anthocyanin, only to its quantity and pattern of distribution.

The other spots, which could be seen on viewing under ultraviolet light, were, with one exception, common to the mutants and to Pal plants. Most of them could be identified by reference to published results on chromatography of Antirrhinum pigments, especially to Harborne ( 1963 ). One pigment, labelled 8 in fig. I, did not seem to have been previously reported. It was conspicuously present in extracts of all flowers homozygous for recessive pal alleles (including $p a l^{r u b}$ ) but was not present, or present only in a barely detectable quantity, in $\mathrm{Pal}$ plants. This pigment was isolated by successive chromatographic steps on Whatman 3 MM paper from flowers of the (low) palrec stock. It proved to be chromatographically identical in three solvents (BAW, 15 per cent. acetic acid and water-saturated phenol) to quercetin 3-rutinoside (rutin). The identification was confirmed by hydrolysis of the pigment in $\mathrm{N} \mathrm{HCl}$. The flavonol aglycone, extracted from the hydrolysate with ethyl acetate, was inseparable from quercetin in two chromatographic solvents (BAW and acetic acid-concentrated $\mathrm{HGl}$-water, 30:3: ro by volume). The 


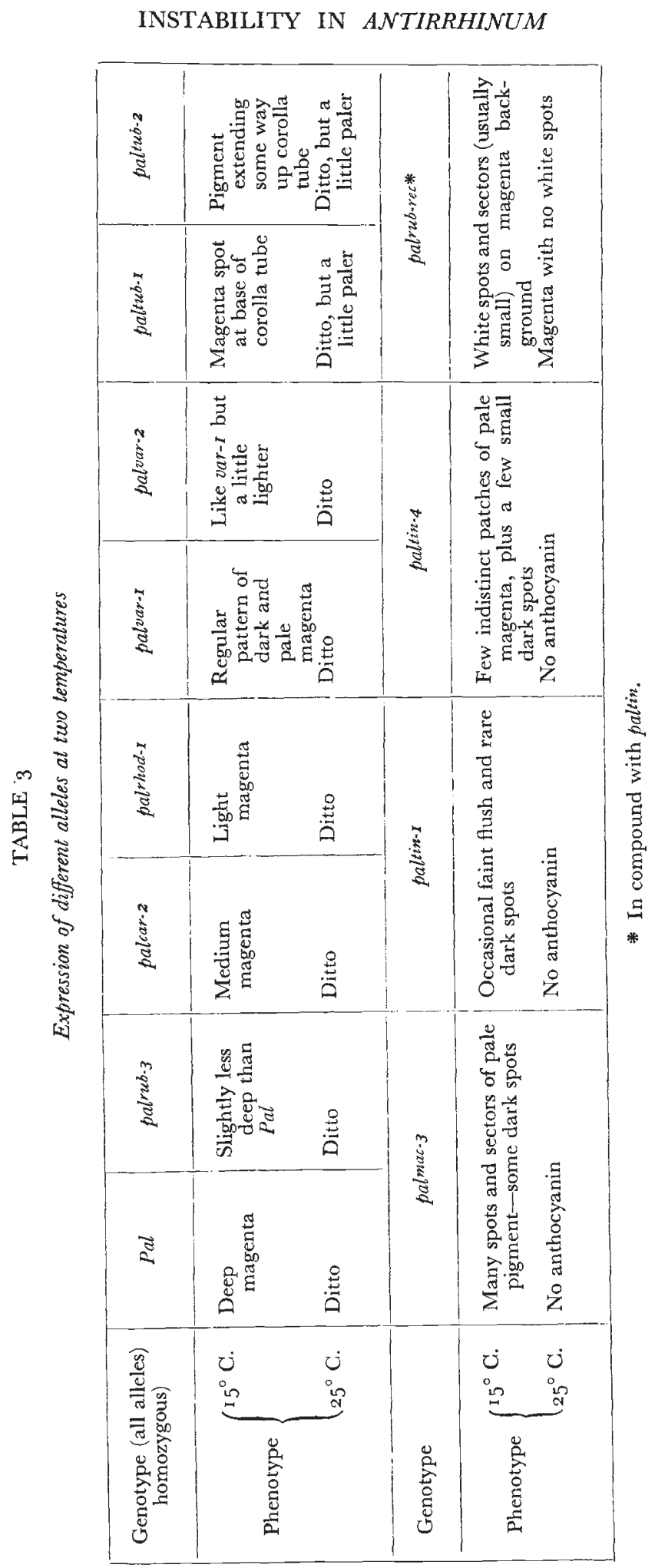


aqueous residue was analysed chromatographically for sugars and two sugar spots, visualised by the aniline phthalate reagent, proved to be inseparable from glucose and rhamnose respectively in BAW and in $n$-butanol-benzene-pyridine-water $(5: 1: 1: 3$ by volume). The absorption spectrum of the pigment was determined in the original ethanolic solution and showed maxima at 259 and $363 \mathrm{~m} \mu$. After saturation of

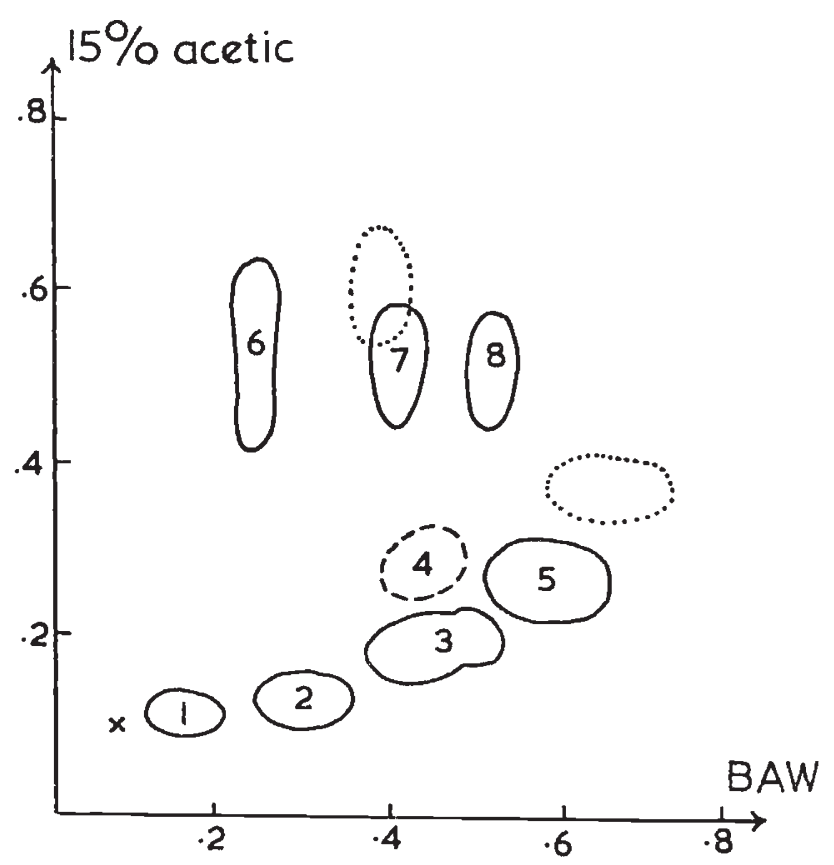

FIG. I.-Diagram showing chromatographic positions of pigments, based on tracings of chromatograms. The position of application of the sample is marked $\mathrm{X}$ and the figures along each axis represent RF values. Spot 7 was magenta and spots $I$ and 2 yellow viewed in ordinary light. Under ultraviolet light $\mathrm{I}$ and 2 fluoresced bright green and spots $3,4,5,6$ and 8 were dark brown. On exposure to ammonia vapour spots $3,4,5$ and 8 turned yellow or yellow-green in ultraviolet light while 6 remained brown. Spots 4 and 6 were generally distributed but rather variable; spot 6 was especially strong in material grown in a hot greenhouse. Dotted spots were faint and variable. Spot 8 was seen with certainty only in plants homozygous for recessive pal alleles, and spot 7 only in plants with magenta colour in the flowers; other spots were seen in all genotypes. The identification of the spots, based tentatively on Harborne (1 963 ) or, in the case of spot 8, described in this paper, is as follows: (I) bracteatin 6-glucoside, (2) aureusidin 6-glucoside, (3) chrysoeriol 7-glucuronate plus luteolin 7-glucuronate,

(4) quercetin 3-glucoside, (5) apigenin 7-glucuronate, (6) apigenin 7,4'-diglucuronate,

(7) cyanidin 3-rutinoside, (8) quercetin 3-rutinoside (rutin).

the solution with sodium acetate the maxima shifted to 273.5 and $395 \mathrm{~m} \mu$ and, after further saturation with boric acid, to 263 and $3^{82.5} \mathrm{~m} \mu$. These results leave no doubt that the pigment is rutin.

It seems that plants homozygous for recessive pal alleles have either a partial or a complete impairment of synthesis of cyanidin 3-rutinoside and produce quercetin 3-rutinoside instead. This conclusion was strengthened by the finding that full red mutant shoots on $p a l^{r e c} / p^{2} l^{r e c}$ plants did not produce rutin in appreciable quantity-the gain in 
ability to make the anthocyanin resulted in loss of ability to accumulate the flavonol analogue. The structures of the two pigments are shown below.

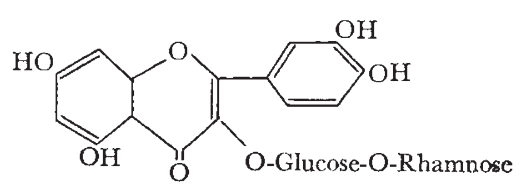

Quercetin 3-rutinoside (rutin)

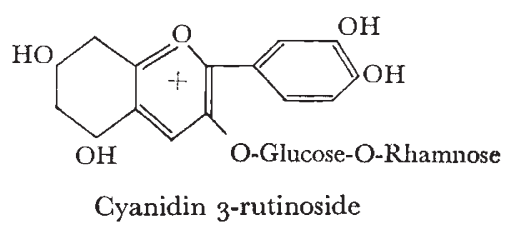

Cyanidin 3-rutinoside

\section{DISCUSSION}

In the absence of any certain knowledge of the enzyme-catalysed reactions involved in anthocyanin synthesis it is not possible to specify the function of the pal locus in enzymological terms. However, the fact that the pal mutants all form appreciable amounts of rutin, while $P a l$ plants do not, suggests that there is a common rutinoside precursor of both rutin and cyanidin 3-rutinoside, and that when the conversion of the precursor to the anthocyanin is partially or completely blocked it is converted to rutin instead. The precursor could conceivably be rutin itself, though no evidence for a direct utilisation of rutin for anthocyanin synthesis has ever been produced. The common ivory type of Antirrhinum majus, homozygous for the recessive allele at the incolorata (inc) locus, does not produce rutin, though quercetin 3-glucoside is present in such plants (Jorgensen and Geissman, I955). It may be that a common precursor of both quercetin and cyanidin, perhaps a chalcone derivative, is normally converted sequentially to the 3-glucoside and the 3 -rutinoside, that either of these glycoside intermediates can be converted to the corresponding quercetin glycoside but that only the rutinoside serves as a precursor of its cyanidin analogue. On this view inc/inc plants are blocked in the addition of rhamnose to the precursor glucoside to form the rutinoside, while pal mutants are more or less deficient in the further conversion of the rutinoside to the cyanidin derivative. All the evidence is consistent with the different $p a l$ alleles affecting the same biosynthetic step in different degrees, but it is not possible to say whether they produce different structural variants of the enzyme concerned or different quantities of a common structure. If, as is suggested below, pal has a regulatory rather than a structuredetermining function the second alternative will be true. There is a pressing need for information on the intermediates and enzymes of anthocyanin synthesis which would enable these possibilities to be tested.

The alleles compared in this study differ from each other either in the quantity of the pigment which they determine, or in its pattern of distribution, or in both respects. Distinctive patterns may be stable (e.g. pal ${ }^{t u b}, p a l^{v a r}$ ) or apparently due to mutation, with pigment appearing in more or less randomly distributed groups of cells (e.g. pal $l^{\text {mac }}$ and some occurrences of $\left.p a l^{t i n}\right)$. The two kinds of pattern respond quite 
differently to temperature changes. The action of those alleles which cause patterns of a stable and reproducible kind ( $p a l^{t u b}, p^{\text {var }}$ ) as well as of those which produce characteristic levels of more uniform pigmentation ( $\mathrm{pl}^{r u b}, \mathrm{pal}^{\mathrm{car}}, \mathrm{pal}^{l^{\text {rhod }}}$ ), is unaffected or very little affected by temperature shifts between $\mathrm{I} 5^{\circ} \mathrm{C}$. and $25^{\circ} \mathrm{C}$. In contrast, the random spotting and sectoring associated with pal $^{\text {rec }}$, pal ${ }^{\text {mac }}$ and some alleles of the paltin class is suppressed or very greatly reduced at $25^{\circ} \mathrm{C}$. The observation that the mutation of pal rub-rec resembles that of pal rec in being suppressed at $25^{\circ} \mathrm{C}$., even though the two alleles mutate in opposite directions with respect to pigment intensity, is noteworthy. In the mutation of pal ${ }^{m a c-3}$ to pal $^{\text {var-2 }}$ we see very strikingly a change from a mutable pattern which is suppressed at $25^{\circ}$ C. to a stable mutant pattern relatively insensitive to temperature change. The presence or absence of a strong temperature effect seems to be a good criterion for distinguishing stable from mutational patterns in cases where the classification of the mutant is not immediately obvious.

These observations tend to suggest that there are two rnutable components of the pal locus. The first may be regarded as a regulator component, which sets the level of activity of the gene and which is relatively insensitive to temperature, although it may respond to gradients of various kind within the flower to produce characteristic stable patterns, and the second as a mutator element, highly sensitive to temperature. Such an interpretation is reminiscent of the two components of Suppressor-mutator $(S p m)$ in maize postulated by McGlintock ( I $_{65}$ ). Broadly speaking, component-I is thought to control the activity of the gene responding to $S p m$, while component-2 determines its mutability. The analogy is all the closer in that McClintock has found a dominant modifier, unlinked to $S p m$, which greatly increases the frequency of mutations determined by component-2, whereas we (Harrison and Fincham, in preparation) have identified a semi-dominant modifier which has a large effect on the mutation frequency of at least our original pal rec alleles. In fact, the difference between the (low) and (high) palrec stocks is largely due to this modifier. A major difference between the two systems, which may or may not be fundamental, is the fact that the $S p m$ complex can control the activity and mutation of genes, such as $a_{1}$ which are not linked to it, while all the mutations determined by the postulated pal mutator element are at or close to the pal locus itself.

While a regulator component such as may exist at pal can be readily imagined to have a normal physiological function, a normal, as opposed to a pathological, role for a mutator element is not so easily envisaged. It is possible to regard the high mutability as a sort of disease. Against this point of view is the close association which evidently prevails between the postulated mutator and regulator components. Both appear to mutate together. For instance, the one step change from palrec to pal ${ }^{\text {car }}$ involves both a change in the regulator setting and a loss of the obvious mutability. While such an observation 
can be explained away by saying, as McClintock does in the Spm case, that the activity of one component is dependent on the state of the other, a close functional integration of the two components is still implied. Rather than postulating two physically distinct regulator and mutator elements it seems equally valid, and rather more attractive, to regard them as different functions, or different modes of variation, in a single unit, no part of which can be altered without an effect on the whole.

It is tempting to regard the mutability as representing one aspect of the normal mechanism for regulating gene activity. In other words the mutable alleles mutate because it is part of the function of the normal gene to mutate, albeit in a more controlled way. This point of view has been suggested on several occasions by McClintock (e.g. I 96 I). What is envisaged is a regulator associated with the gene (or perhaps, in some cases, acting on it at a distance) which ensures that the gene activity is "switched on" at a predetermined intensity in certain tissues at certain precisely controlled times. This "switching-on " can be envisaged as a mutation, in the sense of a self-replicating change in the state of the DNA so that the active form of the gene is transmitted in a stable fashion to progeny cells.

On the basis of these speculations the following interpretation is suggested.

Mutable alleles, which in their unmutated condition show low or null levels of gene activity, are due to changes in the regulator such that it has lost its capacity to respond to the conditions which normally trigger gene activity. This "super-repressed" state is self-replicating just like the normally-repressed and switched-on states. The conditions favouring mutation from super-repressed to normally-repressed may well be different from those which induce the change from the latter state to the switched-on condition, though they may have something in common. Further, the escape from the super-repressed condition may take place in the sub-epidermal cell layer which gives rise to the germ cells and in which the normal switching-on of the pal gene does not occur. Finally, the mutation of super-repressed alleles does not always lead to a normal allele but sometimes to another mutant allele.

These speculations may become more testable when more is known about the biochemistry of the system. In particular one would like to know about the enzyme controlled by pal and the way in which it varies in response to allelic substitutions. Even more to the point, in view of the suggestion that different alleles derived in mutable systems may represent different numbers of units of a variable self-replicating element (Brink, I 964), would be information on the effects of inhibitors of DNA synthesis on the mutation of unstable alleles.

\section{SUMMARY}

I. A number of phenotypically distinct mutants, all with more or less impaired anthocyanin pigmentation of the flower arose in plants 
carrying the mutable allele pallida-recurrens. The mutations concerned were all at, or close to, the pal locus.

2. The new series of multiple alleles determine various levels of pigmentation and various patterns; some of the latter appear to be due to somatic mutability, while others are stable. The stable patterns are very little affected by temperature changes between $15^{\circ} \mathrm{C}$. and $25^{\circ} \mathrm{C}$. but the mutational ones are suppressed at $25^{\circ} \mathrm{C}$.

3. Most of the mutable alleles appear to mutate most frequently to the "wild type" $\mathrm{Pal}$, but some show preferential mutation to specific stable mutant alleles. In most cases the instability takes the form of mutation from absence to presence of anthocyanin, but one allele shows mutation in the reverse direction.

4. All the pal mutants produce the same anthocyanin (cyanidin 3 -rutinoside) though in amounts which vary widely from allele to allele. All, unlike mutants at any other locus so far as is known, produce rutin (quercetin 3-rutinoside) in appreciable amounts. The impairment of the formation of the anthocyanin seems, therefore, to be associated with the accumulation of the analogous flavanol derivative.

5. The possible relationship of mutability to normal gene action is discussed.

Acknowledgment.-We wish to thank Miss Rosemary Carpenter for excellent assistance throughout the work and Mr Peter Slarke for assistance with the chromatographic analysis of pigments. Mr L. S. Clarke was responsible for the photograph.

We are also grateful to Dr. J. B. Harborne for valuable advice on identification of pigments.

\section{REFERENCES}

BRINK, R. A. 1964. Genetic repression of $R$ action in maize. Symp. Soc. Study Develop. Growth, 23, 183-230.

HARboRne, J. B. I 963 . Plant polyphenols. X. Flavone and aurone glycosides of Antirrhinum. Phytochemistry, 2, 327-334.

HARRison, B. J., AND FINCham, J. R. s. I 964 . Instability at the Pal locus in Antirrhinum majus. Heredity, 19, 237-258.

JORGENSEN, E. C., AND GEISSMAN, T. A. 1955. The chemistry of flower pigmentation in Antirrhinum majus. II. Glycosides of PPmm $Y$, $P P M M Y Y$, ppmm $Y \Upsilon$ and ppMMYY color genotypes. Arch. Biochem. Biophys., 54, 72-82.

KUCKUCK, H., AND SCHICK, R. 1930. Die Erbfaktoren bei Antirrhinum majus und ihre Bezeichnung. Z.I.A.V., $56,5 \mathrm{I}-83$.

MCCLINTOCK, B. 196I. Some parallels between gene control systems in maize and in bacteria. Amer. Nat., 95, 265-77.

MCCLINTOCK, в. 1965. The control of gene action in maize. Brookhaven Symposia in Biology, 18 (Genetic Control of Differentiation), 162-184.

SCOTt-MONCRIEFF, R. 1930. The magenta flower pigment of Antirrhinum majus. Biochem. 7., 24, 753-- 


\section{Plate I}

Flowers of different genotypes, grown in the greenhouse

Top row, left to right: (low) pal rec/pal rec del/del, (high) pal ${ }^{\text {rec }} / \mathrm{pal}^{\text {rec }}$ del/del, pal in i $1 /$

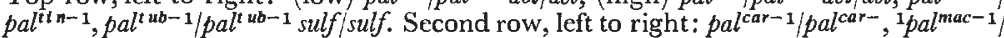

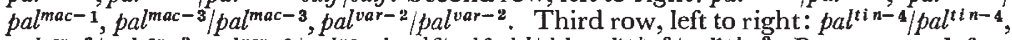
palcar-2/palcar-2, pal var-1/palvar-1 sulf $/$ sulf, del/del, palt ub-2 $/$ pal $^{\text {t ub-2 }}$. Bottom row, left to

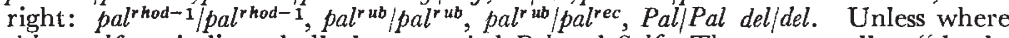
del or sulf are indicated all plants carried Del and Sulf. The strong yellow " background "in the palvar-1 flower shown somewhat obscures the anthocyanin pattern in this photograph, and the homozygosity for del prevents the expression of the characteristic var pattern in the tube. The unnumbered $r u b$ allele was one isolated subsequent to the main experiment and it has not been thoroughly checked genetically, but it appears very similar to other rub alleles. 


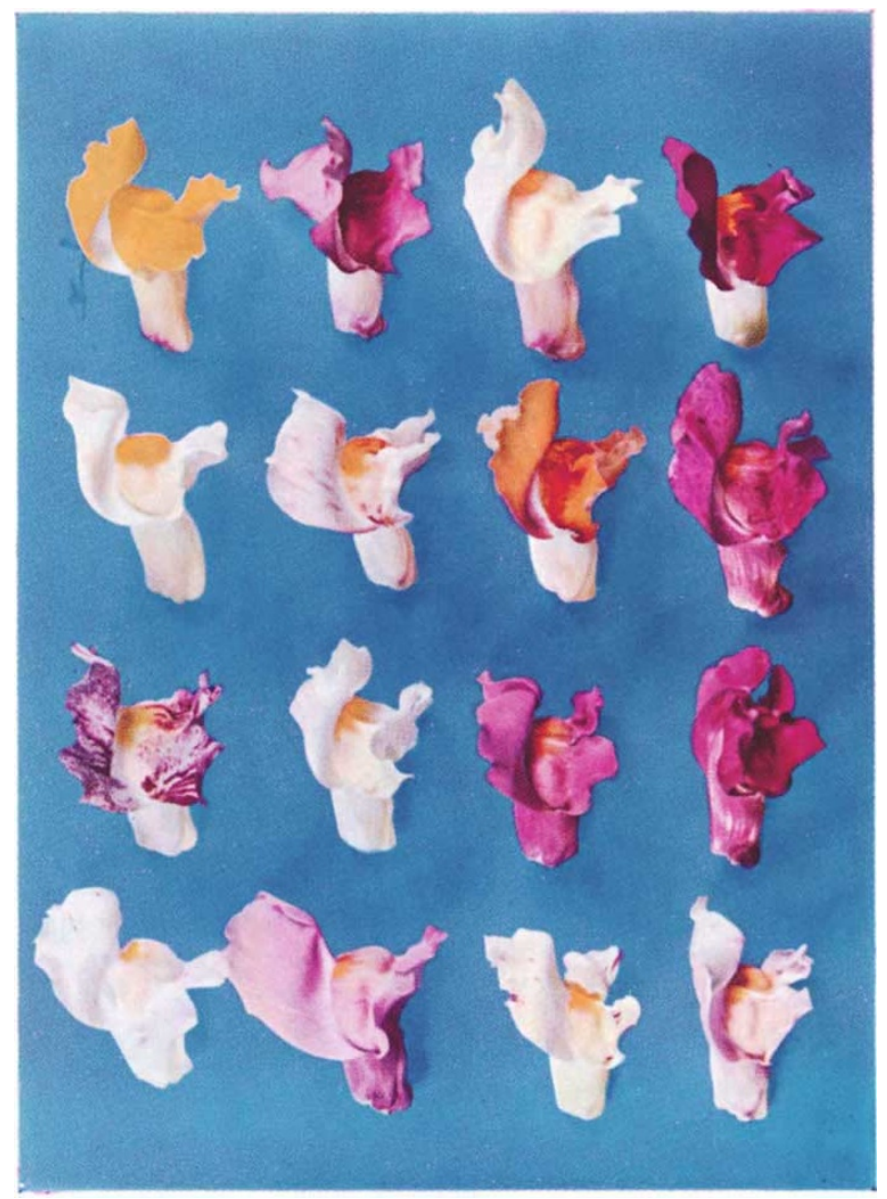

